\title{
Synthesis of Highly Ordered Mesoporous MCM-41: Selective External Functionalization by Time Control
}

\author{
Ana Claudia P. da Silva, ${ }^{\circledR a}$ Patrícia H. Y. Cordeiro, ${ }^{b}$ Bianca M. Estevão, ${ }^{a}$ \\ Wilker Caetano, ${ }^{a}$ Hellmut Eckert, ${ }^{c}$ Silvana M. O. Santin, ${ }^{\oplus *, a}$ Murilo P. Moisés, ${ }^{d}$ \\ Noboru Hioka ${ }^{a}$ and André L. Tessaro ${ }^{d}$ \\ ${ }^{a}$ Departamento de Química, Universidade Estadual de Maringá, 87020-900 Maringá-PR, Brazil \\ ${ }^{b}$ Departamento de Engenharia Química, Universidade Estadual de Maringá, \\ 87020-900 Maringá-PR, Brazil
}

'Grupo de Ressonância Magnética, Espectroscopia e Magnetismo, Instituto de Física de São Carlos, Universidade de São Paulo, 13566-590 São Carlos-SP, Brazil

${ }^{d}$ Departamento de Química, Universidade Tecnológica Federal do Paraná, Campus Apucarana, 86812-460 Apucarana-PR, Brazil

Sol-gel synthesis is commonly used to modify the surface of mesoporous silica nanoparticles (MSN) with organic groups through the co-condensation method. The template removal, and the site-controlled addition of organic groups and their partial occlusion inside the framework walls are still a challenge in the one-pot synthesis. Here, we optimize the synthesis of amino-modified MSN by the combination of efficient template removal methodology with the precise time of the amino precursor addition to achieve superb mesoporous material. The addition after the growth process produces a sample with a significantly higher amount of $\mathrm{NH}_{2}$ on the external surface when compared to the standard procedure. The template removal by reflux with isopropanol $/ \mathrm{H}^{+}$ eliminated ca. $90 \%$ of cetyltrimethylammonium bromide (CTAB), and preserved the mechanical and thermal properties, even with thin walls $(2.1 \mathrm{~nm})$. The synthesized nanoparticles possess stability, appropriate size, and a positive surface. This makes them excellent nanocarriers, especially in the biomedical field.

Keywords: MCM-41, mesoporous silica nanoparticles, co-condensation method, template removal

\section{Introduction}

Mesoporous silica nanoparticles (MSN) possess high specific areas and ordered/regular pore distribution. ${ }^{1-3}$ This makes them versatile materials that can be applied in adsorption, chromatography, catalysis, chemical sensors, and drug delivery systems in the biomedical field. ${ }^{4,5}$ In Mobil composition of matter No. 41 (MCM-41) synthesis, one of the most used silica mesoporous materials, the surfactant cetyltrimethylammonium bromide (CTAB) acts as the structure-directing agent (template). Ordered mesoporous MCM-41 is synthesized through hydrolysis and condensation of silicon alkoxides by a mechanism that includes nucleation and growth steps. ${ }^{6,7}$

*e-mail: smoliveira@uem.br
The use of MCM-41 in technological applications is particularly attractive due to the easy chemical manipulation, control of parameters such as pore/particle size, and the possibility of surface functionalization. A common methodology for MSN functionalization is the grafting technique, where functional groups are chemically bound to the structure after the complete template (CTAB) removal by calcination. However, this method results in non-homogeneous distribution with these groups, as they are mainly bonded to the inner surface of the pores. This inner location leads to a steric hindrance which restricts the substrate adsorption in the pores. ${ }^{8,9}$

Alternatively, sol-gel synthesis allows for the modification of the MSN surface with organic groups through the co-condensation method (one-pot). In this methodology, the functional groups are incorporated 
directly into the silica framework during the synthesis. ${ }^{1}$ Yokoi et al..$^{10}$ reported that the co-condensation method leads to a more homogeneous distribution of the functional groups in the silica matrix. However, the presence of these groups can affect the degree of MCM-41 mesoscopic ordering. Moreover, this method leads to partial organic group occlusion inside the framework walls, as illustrated in Figure $1 .{ }^{11}$ Kecht et al. ${ }^{12}$ showed that by delaying the addition of the functional organic group, they can be bonded preferentially in the external part. Their findings showed that the addition of 3-aminopropyltriethoxysilane (APTES) after $30 \mathrm{~min}$, in a total synthesis of $12 \mathrm{~h}$, favors the orientation of $\mathrm{NH}_{2}$ groups to the external surface.

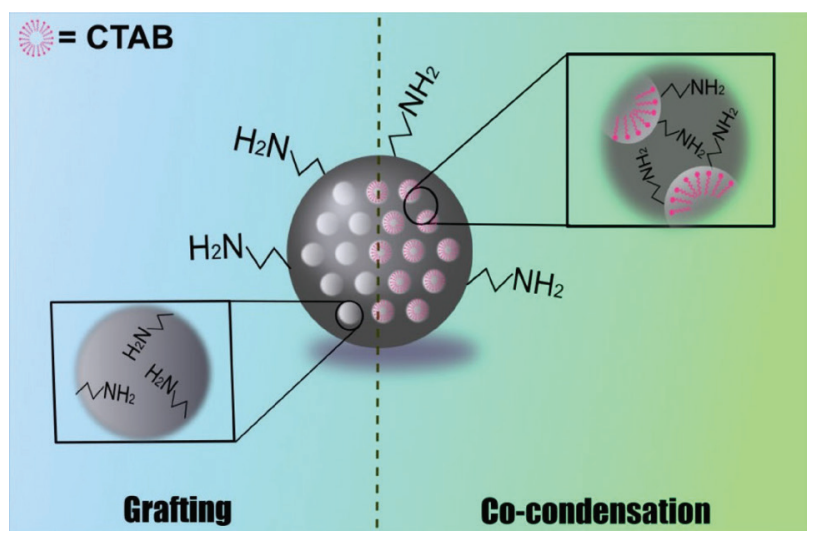

Figure 1. Schematic illustration of the possible amine groups location on the $\mathrm{NH}_{2}-\mathrm{MSN}$ framework synthesized through grafting and cocondensation (one-pot) methods.

After the hydrothermal step in a common synthesis, the surfactant is removed by calcination. However, in the one-pot synthesis, the extraction of the template must be performed through ion-exchange, avoiding the degradation of organic groups that are already connected. One of the most commonly used extraction methods are Soxhlet and stirring, both of which are normally performed in acidic methanol or ethanol. ${ }^{13-15}$ Another approach used is the reflux method, which is usually performed with methanol or ethanol in acidic media for $24 \mathrm{~h} \cdot{ }^{14,16-19}$ It is also known that, depending on the chosen method, the extraction of the CTAB surfactant can be incomplete, compromising the system due to its toxicity (in the case of biological application) and pore blockage. ${ }^{20,21}$ Pérez et al..$^{22}$ also showed that the surface tension of the solvent influences shrinkage and loss of MCM-41 ordering.

Although it seems simple, controlled functionalization of MSN associated to an efficient extraction method that preserves the high order of the material is not a trivial task. The examples in the literature ${ }^{12,20}$ generally face these challenges separately, as aforementioned. Especially in the biomedical field, the obtaining of homogeneous particles (with minimal template residue and available groups for post-functionalization) is highly desired.

Thus, the focus of this study is to optimize the synthesis of amino-modified MSN by the combination of efficient template removal methodology with the precise time of the amino precursor addition. This is performed with the objective of achieving a superb mesoporous material. We achieved this objective by adding APTES after the growing process and removing the template by reflux with isopropanol $/ \mathrm{H}^{+}$, which eliminated ca. $90 \%$ of CTAB and preserved the mechanical and thermal properties, even despite thin walls $(2.1 \mathrm{~nm})$.

\section{Experimental}

\section{Materials}

$\mathrm{N}$-Cetyltrimethylammonium bromide (CTAB), sodium hydroxide $(\mathrm{NaOH})$, tetraethoxysilane (TEOS), bovine serum albumin (BSA), hydrochloric acid $(\mathrm{HCl})$, and isopropanol were purchased from Sigma-Aldrich. APTES was purchased from Tedia Brazil. All other reagents and solvents exhibited high purities and were used without further purification.

Synthesis of amino functionalized mesoporous silica nanoparticles

Amino-modified MSN were synthesized by the co-condensation method of TEOS and APTES, according to the methodology described by Wada et al. ${ }^{14}$ Briefly, CTAB (1.92 mmol) was dissolved in $340 \mathrm{~mL}$ of distilled water. After, $2.45 \mathrm{~mL}$ of an aqueous solution of $\mathrm{NaOH}$ $(2.0 \mathrm{M})$ was added to the CTAB solution, followed by the heating of the mixture to $80^{\circ} \mathrm{C}$. Finally, TEOS $(3.5 \mathrm{~mL}$, $15.8 \mathrm{mmol})$ and APTES $(0.43 \mathrm{~mL}, 1.84 \mathrm{mmol})$ were slowly added (by drops) to the solution. The mixture was kept under stirring at $80{ }^{\circ} \mathrm{C}$ for $2 \mathrm{~h}$, which created white precipitates $(\mathrm{MSN}+\mathrm{CTAB})$. The solid product was filtered with a vacuum system, washed with deionized water and ethanol, and dried at $60{ }^{\circ} \mathrm{C}$ for $24 \mathrm{~h}$.

\section{Template removal procedures}

For template removal, Soxhlet and reflux methodologies were evaluated using acidic isopropanol (2 drops of commercial $\mathrm{HCl}$ ), which kept the material concentration at $4 \mathrm{mg} \mathrm{mL}^{-1}$. Reflux methodology was performed after 12 (MSN_R12) and $24 \mathrm{~h}$ (MSN_R24), while Soxhlet ${ }^{23}$ was performed for $96 \mathrm{~h}$ (MSN_S). Non-functionalized MSN containing CTAB (MSN_CTAB), or calcined (MSN_C) 
under static conditions at $550{ }^{\circ} \mathrm{C}$ for $6 \mathrm{~h}\left(1{ }^{\circ} \mathrm{C} \mathrm{min}{ }^{-1} \mathrm{ramp}\right),{ }^{24}$ were used as references.

\section{Addition of APTES in different reaction times}

For these experiments, MSN were synthesized as described above. However, the addition of the APTES was performed in three different times: time "zero" (MSN_0R12), after 60 min (MSN_60R12), and after 90 min (MSN_90R12) of synthesis. In all cases, the reaction was maintained for $120 \mathrm{~min}$.

\section{Studies of protein loading}

The BSA adsorption assays of the nanoparticles (MSN_0R12, MSN_60R12, and MSN_90R12) were performed by mixing $1.0 \mathrm{mg}$ of MSN in phosphate buffer ( $\mathrm{pH}$ 7.4) with $4.0 \mathrm{~mL}$ of BSA solutions at different concentrations $\left(0.2-1.0 \mathrm{mg} \mathrm{mL}^{-1}\right)$. All samples were shaken for $2 \mathrm{~h}$ at an ambient temperature, and then particles were precipitated by centrifugation..$^{25}$ The absorbance of protein in supernatants was determined at $280 \mathrm{~nm}$, and the adsorbed amount of protein was calculated by mass balance.

\section{Characterization methodologies}

The morphology of the particles was investigated using a JEOL JEM-1400 TEM (transmission electron microscope). For these analyses, the samples were quickly sonicated and added in copper grids. The size, pore diameter and homogeneity of the nanoparticles were performed using Image-Pro Plus ${ }^{\circledR}$ software. ${ }^{26} \mathrm{X}$-ray diffraction (XRD) patterns were obtained on a Bruker D8 Advance Diffractometer with $\mathrm{Cu} \mathrm{K} \alpha$ radiation $(\lambda=1.54062 \AA$, $40 \mathrm{kV}$ and $35 \mathrm{~mA}$ ) and a scan of $2 \theta$ varying in the range $1-10^{\circ}$ at $0.45^{\circ} \mathrm{min}^{-1}$.

The thermogravimetric (TGA) and differential thermogravimetric (DTG) analyses were performed on a Shimadzu TGA-50 thermogravimetric analyzer. Samples of $5 \mathrm{mg}$ were heated from 30 to $600{ }^{\circ} \mathrm{C}$ at a rate of $10^{\circ} \mathrm{C} \mathrm{min}^{-1}$ under an argon atmosphere $\left(50 \mathrm{~mL} \mathrm{~min}^{-1}\right)$.

Fourier transform infrared (FTIR) spectra were collected with a Bruker Vertex 70v spectrometer at a resolution of $4 \mathrm{~cm}^{-1}$. The IR spectra were recorded in the range of $4000-400 \mathrm{~cm}^{-1}$.

All solid state nuclear magnetic resonance (NMR) experiments were performed on a 5.7 T Varian 240-MR DD2 and a $14.1 \mathrm{~T}$ Bruker Avance Neo spectrometer, using commercially available 2.5 and $4 \mathrm{~mm}$ double and triple resonance magic angle spinning (MAS) probes. ${ }^{29} \mathrm{Si}$ MAS NMR spectra were acquired using $90^{\circ}$ excitation pulses of $5.5 \mu$ s duration, $5 \mathrm{kHz}$ MAS frequency and a recycle delay of $180 \mathrm{~s}$. Chemical shifts are described relative to solid tetrakis(trimethylsilyl)silane (TTMSS) (measured -9.85 ppm relative to trimethylsilane (TMS)).

To obtain the specific surface area, total pore volume, and average pore diameter, QuantaChrome NOVA equipment was used to measure $\mathrm{N}_{2}$ adsorption/desorption isotherms at $77 \mathrm{~K}$. The samples were activated and degassed by heating at $150{ }^{\circ} \mathrm{C}$ for $24 \mathrm{~h}$. The specific area was calculated with the Brunauer-Emmett-Teller (BET) equation using the relative pressure range of 0.04-0.30. The total pore volume was obtained at $\mathrm{p} / \mathrm{p}_{0}=0.95$, and the pore size distribution was obtained with the non-local density functional theory equilibrium mode (NLDFT). ${ }^{27}$

The temperature-programmed desorption (TPD) of $\mathrm{CO}_{2}$ was performed on Chembet 3000 QuantaChrome equipment, which allowed to estimate the amount of amino groups on the surface of the materials. Initially, the sample was held at $130{ }^{\circ} \mathrm{C}$ for $1 \mathrm{~h}$ to remove adsorbed water molecules. After cooling to $25^{\circ} \mathrm{C}$, the sample was saturated with $\mathrm{CO}_{2}$ for $30 \mathrm{~min}$. To remove the weakly adsorbed $\mathrm{CO}_{2}$, the reactor was kept under nitrogen gas flow at $25^{\circ} \mathrm{C}$ for $3 \mathrm{~h}$. Finally, the TPD curve was obtained by increasing the temperature at a rate of $3{ }^{\circ} \mathrm{C} \mathrm{min}-1$ from 25 to $130{ }^{\circ} \mathrm{C} .{ }^{8}$ Zeta potential was determined by analyzing nanoparticle dispersions in Milli-Q water on a Zetasizer NanoPlus.

\section{Results and Discussion}

Template removal

TEM images (Figure 2) show well-ordered mesoporous materials homogeneously distributed in spherical nanoparticles (insert of Figure 2b) of an average size of $156 \pm 21.3 \mathrm{~nm}$. The micrographs also show typical beehive architecture (Figure 2c) and parallel ordered channels (Figure 2d) characteristic of the hexagonal ordered materials. The pore diameter measurement was also done by microscopy images $(1.8 \pm 0.4 \mathrm{~nm})$. This value is limited by the image contrast and may vary significantly with the orientation of the particle. Even though the value is in line with the estimated by the $\mathrm{N}_{2}$ adsorption/desorption isotherm (see Table 1).

The XRD pattern of MSN_C and MSN_CTAB are presented in Figure 3a. The characteristic reflections indexed to the planes (100), (110), and (200) indicate a high degree of ordering. Figure $3 \mathrm{~b}$ depicts the diffractograms of the samples after template removal. Note that all the samples present typical reflections of the hexagonal mesoporous structure. However, the signals are less 


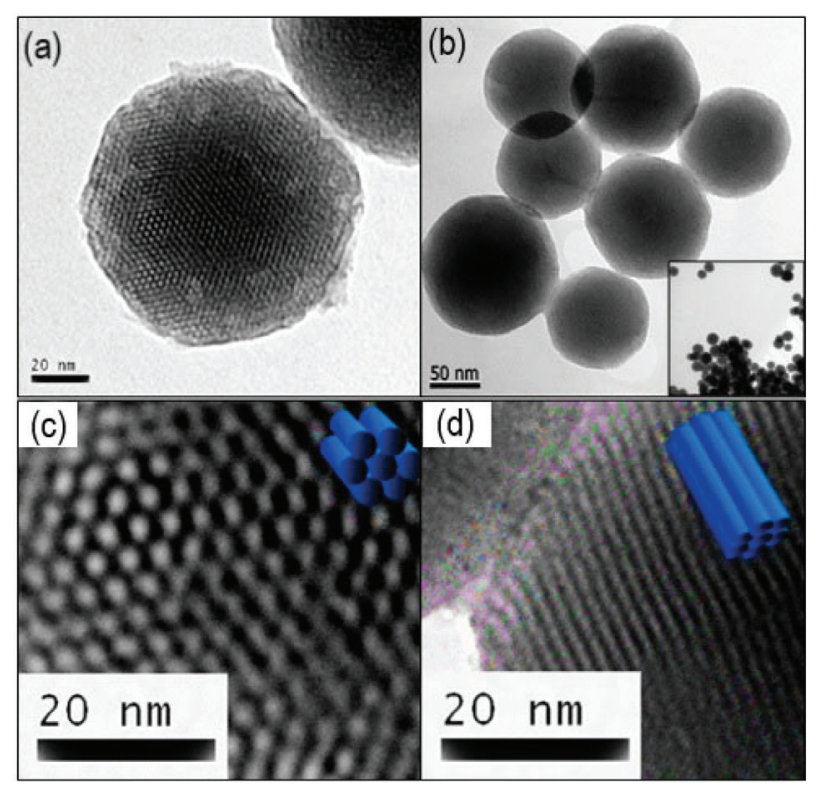

Figure 2. TEM images of (a) and (b) MSN_CTAB; (c) MSN_CTAB with high magnification in longitudinal direction; (d) MSN_CTAB with high magnification in transverse direction of the channels.

intense than MSN_CTAB, especially for MSN_R24, which indicates a reduction of the structural order after extraction.
Though frequently used, ${ }^{13,23,28}$ the Soxhlet methodology possesses low efficiency when removing the template from the mesoporous material, as revealed by the results. In the FTIR spectra of MSN_S, the presence of intense signals at 2920, $2852 \mathrm{~cm}^{-1}$ (symmetrical and asymmetrical stretches of the $\mathrm{CH}_{2}$ and $\mathrm{CH}_{3}$ groups of the CTAB), and $1470 \mathrm{~cm}^{-1}$ (asymmetrical deformation of $\mathrm{CH}_{3}-\left(\mathrm{N}^{+}\right)$groups) demonstrate the presence of substantial quantities of CTAB in the particles (Figure S1, Supplementary Information (SI) section). In fact, only $23 \%$ of the template was removed by Soxhlet, as shown in the thermogravimetric analysis (Figure S2, SI section). Furthermore, the $\mathrm{N}_{2}$ adsorption/ desorption curve (Figure 4) shows an isotherm type II characteristic of non-porous materials, reinforcing the inefficiency of this procedure. A study in the literature ${ }^{29}$ have reported such low efficiency, which can prevent the use of the nanoparticle in the biological environment due to the CTAB toxicity.

The reflux method with the same solvent furnishes better results, as can be seen by the absence of the CTAB signal in the FTIR spectra (Figure S1, SI section) and the high CTAB efficiency extraction calculated by TGA curves: $87 \%$ after

Table 1. Physical and surface properties of the MSNs

\begin{tabular}{lcccccc}
\hline Sample & $\mathrm{d}_{100}$ & $\mathrm{a}_{0}$ & $\begin{array}{c}\text { Specific area } / \\
\left(\mathrm{m}^{2} \mathrm{~g}^{-1}\right)\end{array}$ & $\begin{array}{c}\text { Pore volume / } \\
\left(\mathrm{cm}^{3} \mathrm{~g}^{-1}\right)\end{array}$ & $\begin{array}{c}\text { Average pore } \\
\text { size }(\mathrm{Ps}) / \mathrm{nm}\end{array}$ & $\mathrm{W}_{\mathrm{t}} / \mathrm{nm}$ \\
\hline MSN_CTAB & 4.12 & 4.76 & 28.3 & 0.06 & - & - \\
MSN_C & 4.09 & 4.72 & 1043.8 & 0.62 & 0.65 & - \\
MSN_S & 3.87 & 4.47 & 131.9 & 0.13 & - & 2.07 \\
MSN_R12 & 4.39 & 5.08 & 614.6 & 0.45 & -65 \\
MSN_R24 & 4.50 & 5.20 & 183.2 & 0.22 & - \\
\hline
\end{tabular}

$\mathrm{d}_{100}$ : interplanar distance; $\mathrm{a}_{0}$ : unit cell parameter; $\mathrm{W}_{\mathrm{t}}$ : mesoporous silica nanoparticles (MSN) wall thickness; MSN_CTAB: non-functionalized MSN containing cetyltrimethylammonium bromide (CTAB); MSN_C: calcined MSN; MSN_S: Soxhlet performed for 96 h; MSN_R12: reflux methodology performed after $12 \mathrm{~h}$; MSN_R24: reflux methodology performed after $24 \mathrm{~h}$.
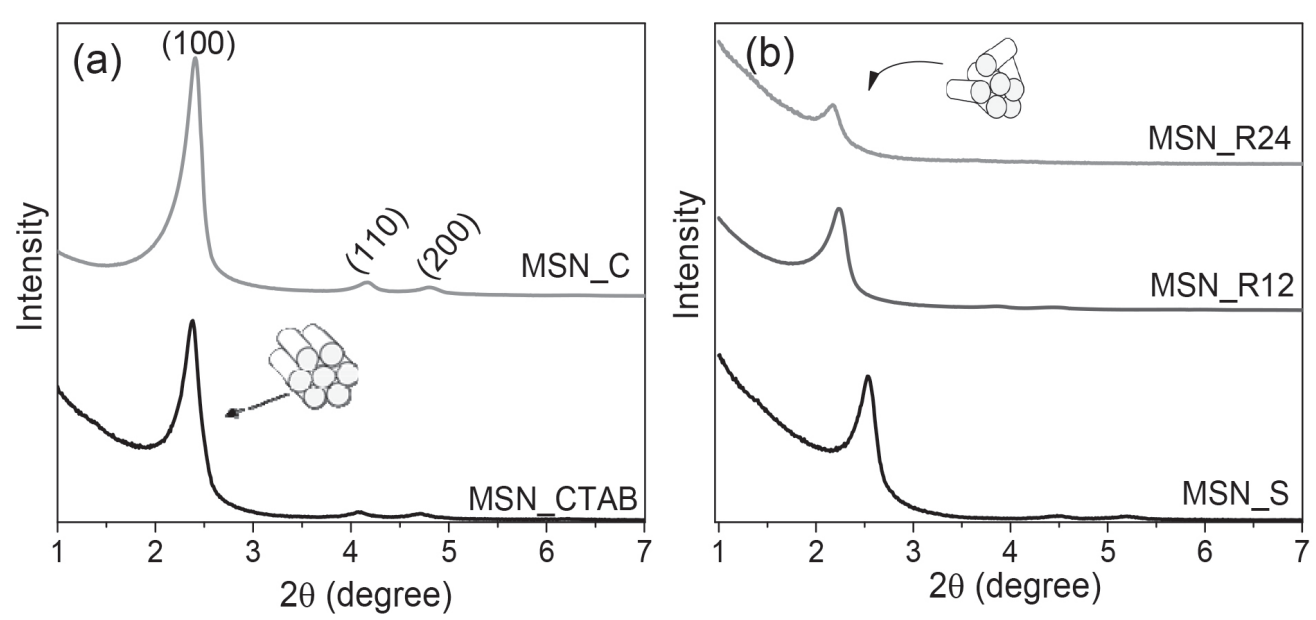

Figure 3. XRD patterns of samples with different template removal procedures. (a) Non-functionalized MSN containing CTAB (MSN_CTAB) and calcined (MSN_C); (b) reflux methodology performed for 12 (MSN_R12) and 24 h (MSN_R24) and Soxhlet performed for 96 h (MSN_S). 


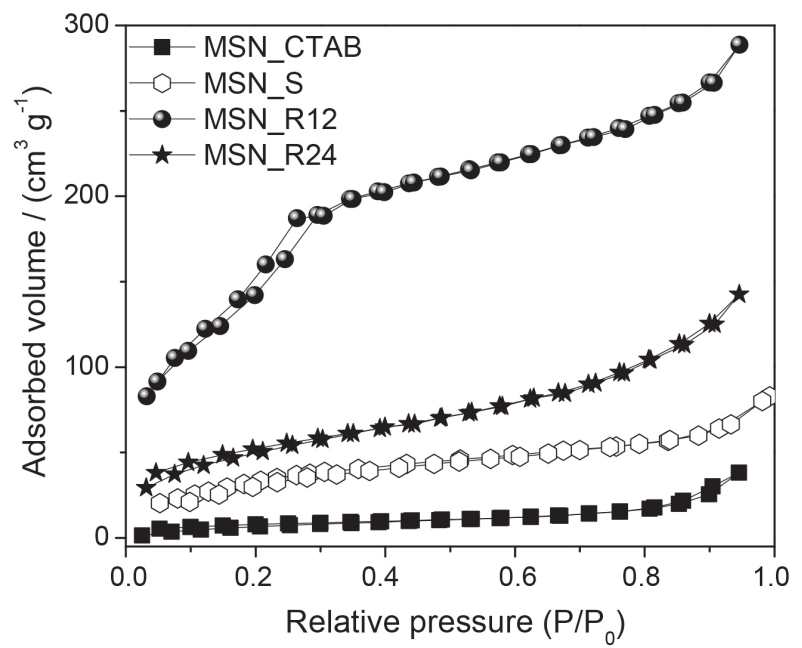

Figure 4. Adsorption and desorption isotherms of $\mathrm{N}_{2}$ at $77 \mathrm{~K}$ for pre (MSN_CTAB) and post-extraction samples (reflux for 12 (MSN_R12) or 24 h (MSN_R24) and Soxhlet for 96 h (MSN_S).

$12 \mathrm{~h}$ and $92 \%$ after $24 \mathrm{~h}$ of reflux. Note that the percentages of removal are comparable with those obtained by the calcination process (ca. 99\%). However, type II isotherms were obtained by $\mathrm{N}_{2}$ adsorption/desorption curves. This rules out the reflux after $24 \mathrm{~h}$ and justifies the loss of structural order previously observed by XRD. The reflux after $12 \mathrm{~h}$ unequivocally shows the best result in this study. Besides high levels of CTAB removal, this condition presents the best results regarding the textural analysis that furnishes a type IVa isotherm with the formation of hysteresis H1. This indicates a narrow size distribution of cylindrical, uniform, and unidirectional mesoporous. ${ }^{27} \mathrm{MSN} \_\mathrm{R} 12$ is the only sample that presents a type IVa isotherm, in addition to the MSN_C used as a reference (Figure S3, SI section). Several studies report the use of reflux methodology to remove the template of mesoporous materials, but scarce information is provided about the specific amount. Commonly, methanol/ $\mathrm{H}^{+14,16}$ or ethanol/ $/ \mathrm{H}^{+17,18}$ are used in a reflux after $24 \mathrm{~h}$. Our procedure greatly reduces the time of heating and uses a less toxic solvent (regarding the methanol). This results in excellent template removal and optimizes the frequently used reflux protocol.

The BET mathematical treatment was applied to calculate the values of specific areas for each sample. Additionally, interplanar distance $\left(\mathrm{d}_{100}\right)$, unit cell parameter $\left(\mathrm{a}_{0}\right)$, average pore size $(\mathrm{Ps})$, pore volume, and MSN wall thickness $\left(\mathrm{W}_{\mathrm{t}}\right)$ were determined through XRD and NLDFT methodology (Table 1). The Ps values are only present in cases where the size exhibits a narrow pore-size distribution (Figure S4, SI section).

The data depicted in Table 1 reinforces the potentiality of the reflux after $12 \mathrm{~h}$ as an excellent methodology for template removal, despite it presents a specific area $40 \%$ lower than the calcined one. In addition, the sample treated with reflux after $12 \mathrm{~h}$ possesses a specific area $370 \%$ larger than the sample treated by Soxhlet, demonstrating again the superior efficiency. Compared to the reflux used in the literature, MSN_R12 presented a specific area equal to that found by Wada et al. ${ }^{14}$ In addition, it required half the extraction time. Thus, among all the template removal methodologies used here, the reflux in acidic isopropanol at $80^{\circ} \mathrm{C}, \mathrm{MSN} \_\mathrm{R} 12$, exhibited the best physical characteristics. It was utilized in the subsequent experiments.

Finally, it is observable that the MSN_R12 presents higher values of wall thickness compared to those in the calcined sample. This may be caused by the premature addition of the APTES (see below), which provokes the incorporation of $\mathrm{NH}_{2}$ groups into the silicate lattice. This makes them partially unavailable for future reactions and reduces the condensation of silicates.

Characterization of MSN after APTES addition at different reaction times

In order to optimize the one-pot synthesis of $\mathrm{NH}_{2}-\mathrm{MSN}$, the influence of time on the incorporation of functional groups into the MCM-41 structure was evaluated. In this form, three MSN syntheses with APTES were conducted: (i) APTES was added at the beginning of the reaction, named MSN_0R12; (ii) APTES was added after 60 min, named MSN_60R12; and (iii) after $90 \mathrm{~min}$, named MSN_90R12. The period of time to complete the reaction was $120 \mathrm{~min}$. All these samples were followed by CTAB extraction with $12 \mathrm{~h}$ of reflux (justifying the nomenclature "R12"). Samples were also analyzed before the CTAB extraction. These samples are MSN_0, MSN_60, and MSN_90, respectively, for APTES added at 0,60, and $90 \mathrm{~min}$.

Figure 5 shows the characteristic diffraction signals of the hexagonal mesoporous structure for all the samples. Note that after the extraction process, the signal intensity significantly increases in the order: MSN_0R12 < MSN_60R12 < MSN_90R12, demonstrating excellent resistance to the extraction process. It should be noted that for the sample MSN_90R12, the XRD intensity was identical to the calcined sample, indicating high order and excellent chemical, thermal and mechanical stability (see below). The reasons are related to the nucleation step during the synthesis of the nanoparticle.

To interpret the XRD results according to the structure at the time of APTES addition (0, 60, and $90 \mathrm{~min})$, three new MSNs without $-\mathrm{NH}_{2}$ and without CTAB extraction were synthesized. These reactions were cut off at 0 , 

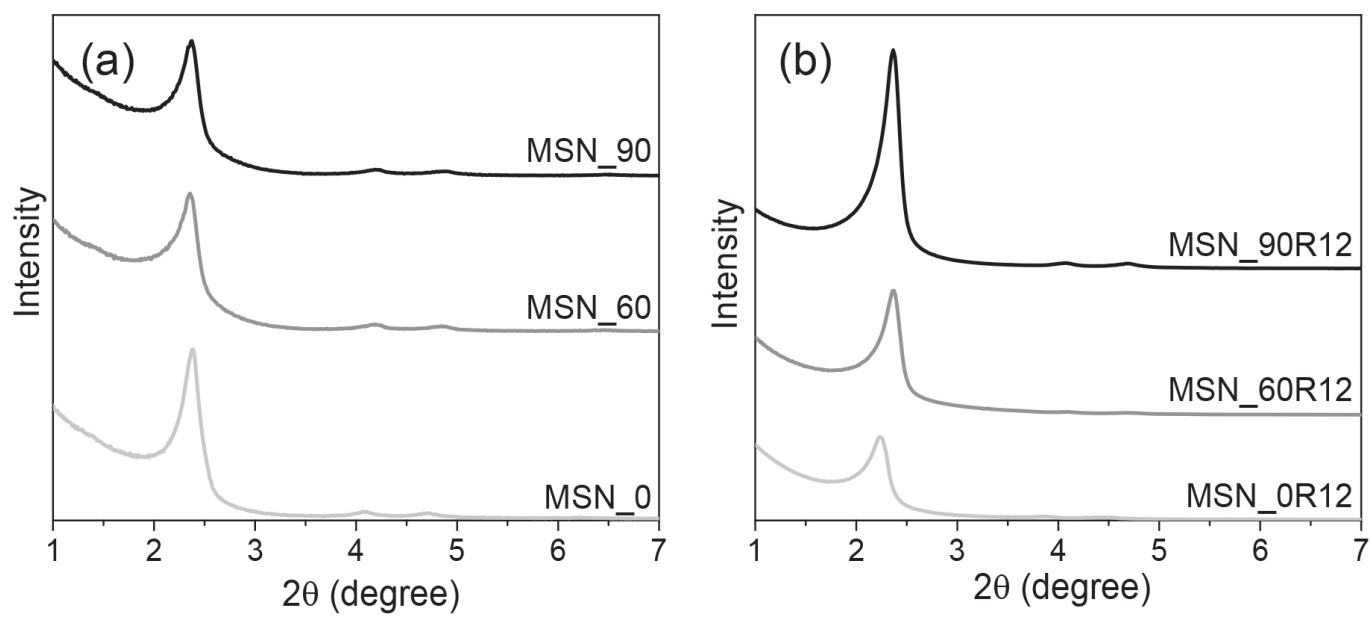

Figure 5. Diffractograms of samples: (a) pre- and (b) post-extraction of CTAB with reflux methodology for 12 h. MSN_0, MSN_60 and MSN_90 refer, respectively, to the time of APTES addition 0, 60 and 90 min after the beginning of the synthesis.

60, and 90 min (samples named as $\mathrm{t} 0^{*}, \mathrm{t} 60^{*}$, and $\mathrm{t} 90^{*}$, respectively). The micrographs are shown in Figure 6.

These structures allowed for the interpretation of what happens when APTES was added in the previous experiments at 0,60 , and 90 min (samples MSN_0R12, MSN_60R12, and MSN_90R12, respectively). TEM showed several tiny particles that presented an average diameter of $4.5 \mathrm{~nm}$ for the sample t $0 *$. However, larger particles were observed when the reaction was interrupted after longer time periods: $89.4 \pm 58 \mathrm{~nm}\left(\mathrm{t} 60^{*}\right)$ and $125.76 \pm 23 \mathrm{~nm}\left(\mathrm{t} 90^{*}\right)$. Therefore, the particle is initially very tiny, but this is followed by a growing stage (Figure 6). These results agree with the mechanism known as nucleation and growth. In the nucleation stage, a lot of small nuclei (seeds) form and act as initial structures. This is followed by subsequent growth. In sequence, these nuclei interact electrostatically with the cationic surface of the micelles. They shield micelle-micelle repulsions, which induces the formation of a hexagonal mesophase. ${ }^{30,31}$

Thus, the low stability of the sample MSN_0R12 can be attributed to the addition of APTES at time zero, which forms tiny nuclei with non-regular structures. Therefore, the presence of $\mathrm{NH}_{2}$ groups in initial stages leads to the formation of deformed and unstable nuclei due to the presence of these heteroatoms interrupting the silicate chains.

After 60 min of reaction, t60* TEM images show a very heterogeneous size distribution and different morphologies, suggesting the existence of simultaneous nucleation and growing steps. Thus, at this step, the sample still shows

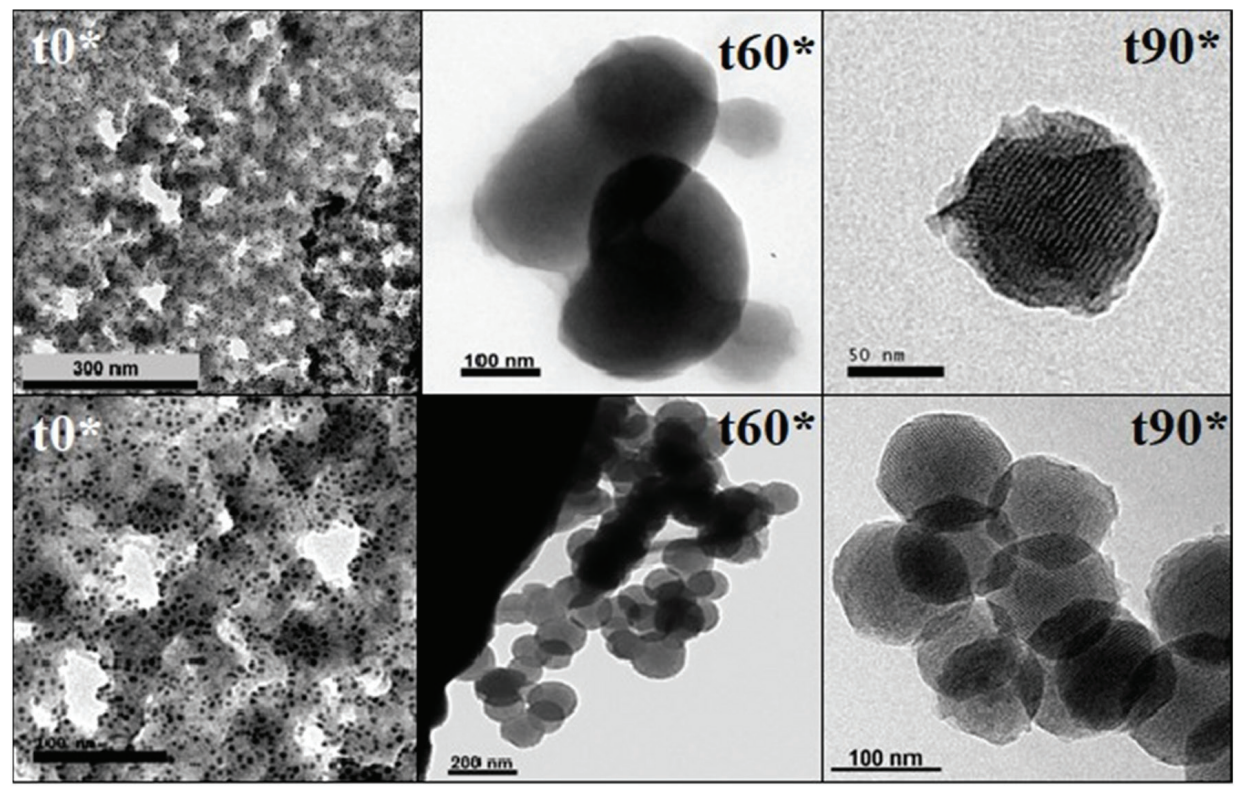

Figure 6. TEM images of samples reactions cut off at $0\left(\mathrm{t} 0^{*}\right), 60\left(\mathrm{t} 60^{*}\right)$ and $90 \mathrm{~min}\left(\mathrm{t} 90^{*}\right)$. The top and the bottom images refer to different expansions of the micrographs. 
tiny and large particles that grow until the end of the reaction, as demonstrated in Figure S5 (SI section). The large heterogeneity observed after $60 \mathrm{~min}$, illustrated by the TEM and the size distribution (Figure S5, SI section), is still a negative moment for APTES addition. Finally, it can be seen that after $90 \mathrm{~min}$ of reaction, only spherical particles were found in the TEM images. They had an average diameter of $125.76 \pm 23 \mathrm{~nm}$, as mentioned before. In the complete syntheses, these particles grew until $2 \mathrm{~h}$ of reaction. Sample t90* shows homogeneous size distribution (Figures 6 and S5, SI section), indicating that this is the adequate experimental condition to add APTES, as performed in samples MSN_90 and MSN_90R12 before the end of the reaction $(2 \mathrm{~h})$. Kecht et al. ${ }^{12}$ also evaluated the time of APTES addition in a co-condensation process. Their contribution focuses mainly in the correlation of the location of amino groups in the particle with the addition time of the functional group. Not much data is provided regarding the stability or the structural order of the particles. They found high density of the functional group on the external surface when the addition occurs at $30 \mathrm{~min}$, but after a $12 \mathrm{~h}$ synthesis.

The TEM assays allowed for the conclusion that the addition of functional groups during initial steps in the MSN formation affects the mechanical and thermal resistance of the final structure. These results are extremely interesting in the optimization of co-condensation synthesis, especially in cases devoted to biomedical usage. The MSN_90R12 sample presented the best XRD results (Figure 5) that can be justified by the functionalization with APTES on regular and homogeneous particles (TEM image in Figure 6, and regular size distribution as demonstrated in Figure S5, SI section).

To evaluate if this variation also affects wall thickness, the $\mathrm{N}_{2}$ adsorption/desorption isotherms were utilized to obtain textural parameters. Very promising results are listed in Table 2 and demonstrate a larger specific area for MSN_90R12. Note that for MSN_90R12, a type IVa isotherm was again observed and its pattern is closer to that of the calcined sample, as seen in Figure S6 (SI section). This result, allied to the XRD and TEM, reinforces MSN_90R12 as the best material, i.e., well ordered mesoporous material with beehive architecture and parallel ordered channels.

The values in Table 2 show that MSN_90R12 presents a specific area that is $42 \%$ higher than MSN_0R12. This feature happened simply by delaying the APTES addition to $90 \mathrm{~min}$. This increment probably is related to the lack of geometric ordering of the MSN_OR12 structure. Sample MSN_90R12 exhibited a remarkable increase of 562\% in specific area compared to MSN_S, as described above. Additionally, while even presenting thinner walls, this sample showed higher mechanical and thermal stability, which is ascribed to the presence of more external amino groups that favored the condensation degree of silicates. ${ }^{7}$

This statement is supported by the ${ }^{29} \mathrm{Si}$ MAS NMR analysis (Figure 7 and Table 3), which shows the evolution of the Q bands in MSN_0R12, MSN_60R12 and MSN_90R12 samples. $\mathrm{Q}^{2}\left(\mathrm{SiO}_{2}(\mathrm{OH})_{2}\right), \mathrm{Q}^{3}\left(\mathrm{SiO}_{3}(\mathrm{OH})\right)$ and $\mathrm{Q}^{4}\left(\mathrm{SiO}_{4}\right)$ bands are assigned at $\delta$ ca. -90 , ca. -100 and ca. $-110 \mathrm{ppm}$, respectively. The addition of APTES at 0 min disturbs the condensation process as evidenced by the low area fraction of $\mathrm{Q}^{4}$ (Table 3 ) and the low ratio $\mathrm{Q}^{4} /\left(\mathrm{Q}^{2}+\mathrm{Q}^{3}\right)=0.9$. However, the addition after $90 \mathrm{~min}$ causes an increase in both the fraction of $\mathrm{Q}^{4}$ (Table 3 ) and the ratio $\mathrm{Q}^{4} /\left(\mathrm{Q}^{2}+\mathrm{Q}^{3}\right)=2.1$. These results demonstrate high condensation degree in MSN_90R12, which gives the material superior chemical and mechanical stability, even after the extraction step. Moreover, the presence of the band at $\delta$ ca. $-68 \mathrm{ppm}$ attributed to the $\mathrm{T}^{3}\left(\mathrm{C}-\mathrm{Si}(\mathrm{OSi})_{3}\right)$ proves the efficiency of amino functionalization, especially for the samples MSN_60R12 and MSN_90R12.

Finally, the amount of available $\mathrm{NH}_{2}$ groups on the surface was determined by the area of each temperatureprogrammed desorption graph (Figure S7, SI section), which furnished the number of basic sites per gram of material. The results showed $1.40 \mathrm{mmol} \mathrm{g}^{-1}$ of $\mathrm{CO}_{2}$ for MSN_C; $2.10 \mathrm{mmol} \mathrm{g}^{-1}$ for MSN_0R12; and $2.75 \mathrm{mmol} \mathrm{g}^{-1}$

Table 2. Physical and surface properties of the samples

\begin{tabular}{lcccccc}
\hline Sample & $\mathrm{d}_{100}$ & $\mathrm{a}_{0}$ & $\begin{array}{c}\text { Specific area / } \\
\left(\mathrm{m}^{2} \mathrm{~g}^{-1}\right)\end{array}$ & $\begin{array}{c}\text { Pore volume / } \\
\left(\mathrm{cm}^{3} \mathrm{~g}^{-1}\right)\end{array}$ & $\begin{array}{c}\text { Average pore } \\
\text { size }(\mathrm{Ps}) / \mathrm{nm}\end{array}$ & $\mathrm{W}_{\mathrm{t}} / \mathrm{nm}$ \\
\hline MSN_CTAB & 4.12 & 4.76 & 28.3 & 0.06 & - & - \\
MSN_0R12 & 4.39 & 5.08 & 614.6 & 0.45 & 2.65 & 2.43 \\
MSN_60R12 & 4.14 & 4.78 & 495.2 & 0.37 & 2.65 & 2.13 \\
MSN_90R12 & 4.14 & 4.78 & 873.2 & 0.54 & 2.65 & 2.13 \\
\hline
\end{tabular}

$\mathrm{d}_{100}$ : interplanar distance; $\mathrm{a}_{0}$ : unit cell parameter; $\mathrm{W}_{\mathrm{t}}$ : mesoporous silica nanoparticles (MSN) wall thickness; MSN_CTAB: non-functionalized MSN containing cetyltrimethylammonium bromide (CTAB); MSN_0R12; addition of the 3-aminopropyltriethoxysilane (APTES) at time "zero"; MSN_60R12: addition of the APTES after $60 \mathrm{~min}$; MSN_90R12: addition of the APTES after $90 \mathrm{~min}$. 

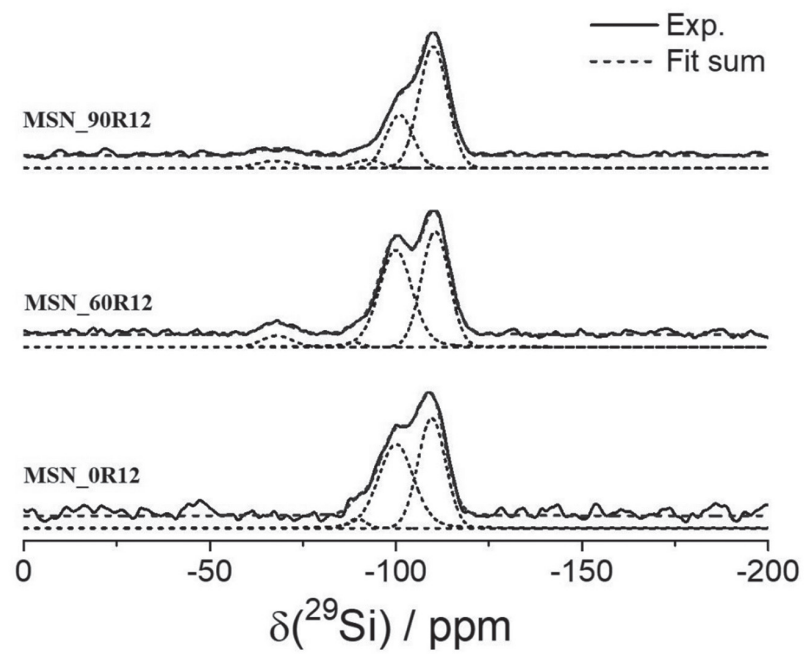

Figure 7. ${ }^{29} \mathrm{Si}$ MAS NMR spectra of the samples MSN_0R12, MSN_60R12 and MSN_90R12.

Table 3. Fit parameters obtained through ${ }^{29} \mathrm{Si}$ MAS NMR

\begin{tabular}{lcccc}
\hline Sample & Band & $\delta / \mathrm{ppm}$ & $\begin{array}{c}\mathrm{FWHM} / \\
\mathrm{ppm}\end{array}$ & $\begin{array}{c}\text { Area } \\
\text { fraction / \% }\end{array}$ \\
\hline \multirow{4}{*}{ MSN_90R12 } & $\mathrm{Q}^{4}$ & $-110 \pm 0.5$ & $9.0 \pm 0.5$ & $64.3 \pm 1.0$ \\
& $\mathrm{Q}^{3}$ & $-101 \pm 0.5$ & $8.5 \pm 0.5$ & $26.5 \pm 1.0$ \\
& $\mathrm{Q}^{2}$ & $-93 \pm 0.5$ & $9.0 \pm 0.5$ & $4.2 \pm 1.0$ \\
& $\mathrm{~T}^{3}$ & $-68 \pm 0.5$ & $12.0 \pm 0.5$ & $5.0 \pm 1.0$ \\
\hline & $\mathrm{Q}^{4}$ & $-110.5 \pm 0.5$ & $9.0 \pm 0.5$ & $45.0 \pm 1.0$ \\
& $\mathrm{Q}^{3}$ & $-100 \pm 0.5$ & $10.0 \pm 0.5$ & $49.0 \pm 1.0$ \\
& $\mathrm{Q}^{2}$ & $-89 \pm 0.5$ & $5.0 \pm 0.5$ & $1.0 \pm 1.0$ \\
& $\mathrm{~T}^{3}$ & $-68 \pm 0.5$ & $9.7 \pm 0.5$ & $5.0 \pm 1.0$ \\
\hline \multirow{4}{*}{ MSN_0R12 } & $\mathrm{Q}^{4}$ & $-110 \pm 0.5$ & $9.0 \pm 0.5$ & $47.4 \pm 1.0$ \\
& $\mathrm{Q}^{3}$ & $-100 \pm 0.5$ & $11.0 \pm 0.5$ & $50.0 \pm 1.0$ \\
& $\mathrm{Q}^{2}$ & $-90 \pm 0.5$ & $5.6 \pm 0.5$ & $2.6 \pm 1.0$ \\
\hline
\end{tabular}

FWHM: full width at half maximum; MSN_90R12: addition of the 3-aminopropyltriethoxysilane (APTES) after $90 \mathrm{~min}$; MSN_60R12: addition of the APTES after 60 min; MSN_0R12; addition of the APTES at time "zero"; $\mathrm{Q}^{2}: \mathrm{SiO}_{2}(\mathrm{OH})_{2} ; \mathrm{Q}^{3}: \mathrm{SiO}_{3}(\mathrm{OH}) ; \mathrm{Q}^{4}: \mathrm{SiO}_{4}$; $\mathrm{T}^{3}: \mathrm{C}-\mathrm{Si}(\mathrm{OSi})_{3}$.

for MSN_90R12. This means that the increase in $\mathrm{CO}_{2}$ adsorption is due to the number of available $\mathrm{NH}_{2}$ groups. According to the amount of starting material used in the synthesis, a yield of $1.84 \times 10^{-3} \mathrm{~mol} \mathrm{~g}^{-1}$ of amino groups was expected. Thus, the TPD data resulted in ca. $73 \%$ of the $\mathrm{NH}_{2}$ groups for MSN_90R12 and only 38\% for MSN_0R12. The result, although qualitative, clearly indicates a greater availability of $\mathrm{NH}_{2}$ groups in the sample MSN_90R12.

Alternatively, the increase in the number of $\mathrm{NH}_{2}$ on the surface is proven by the zeta potential $(\zeta)$, as aminopropyl groups present a $\mathrm{p} K_{\mathrm{a}}$ of $9.8,{ }^{32}$ making them protonated under physiological pH. The $\zeta$ of MSN_0R12, MSN_60R12, and
MSN_90R12 are, respectively, -3.6, 6.5, and $17.7 \mathrm{mV}$. This shows the increase of $\mathrm{NH}_{2}$ at the external surface, with a delay in the functionalization step. All these results are in line with binding experiments performed at physiological $\mathrm{pH}$ with BSA, as this protein is negatively charged at $\mathrm{pH}$ 7.4. The isotherms depicted in Figure S8 (SI section) unequivocally show the higher capacity of the MSN_90R12 to adsorb BSA at the physiological condition.

\section{Conclusions}

The studies demonstrated that the reflux technique with acidic isopropanol for $12 \mathrm{~h}$ results in a high yield of CTAB template extraction (at around 90\%). In addition, the experiments showed that this extraction led to a small disruption to the hexagonal network, while maintaining the primordial characteristics for MCM-41. The evaluation concerning the adequate time to add APTES on the formation of MSN was relevant. TEM images showed that at time zero $(\mathrm{t} 0 *)$, the only silicate nuclei that are present have a diameter of approximately $4.5 \mathrm{~nm}$. The inclusion of organic groups in this step destabilizes the process of nucleation and particle growth. The delay addition of the APTES after 90 min of the beginning of the reaction leads to an excellent ordering mesoporous structure (in the presence of CTAB). This sample demonstrated a higher chemical and mechanical stability to the extraction process, with the XRD being comparable to that of the calcined sample. In the end, the sample exhibited a greater amount of available amino groups for future reactions, which makes it an interesting system for applications in drug delivery, sorption, and catalysis (for example).

\section{Supplementary Information}

Supplementary data are available free of charge at http://jbcs.sbq.org.br as a PDF file.

\section{Acknowledgments}

This work was sponsored by the Brazilian funding agencies Fundação Araucária and UGF (SETI/PR), CAPES and CNPq.

\section{References}

1. Hoffmann, F.; Cornelius, M.; Morell, J.; Fröba, M.; Angew. Chem., Int. Ed. 2006, 45, 3216.

2. Tang, F.; Li, L.; Chen, D.; Adv. Mater. 2012, 24, 1504.

3. Wu, S.-H.; Mou, C.-Y.; Lin, H.-P.; Chem. Soc. Rev. 2013, 42, 3862 . 
4. Chen, F.; Hableel, G.; Zhao, E. R.; Jokerst, J. V.; J. Colloid Interface Sci. 2018, 521, 261.

5. Ma, X.; Feng, H.; Liang, C.; Liu, X.; Zeng, F.; J. Mater. Sci. Technol. 2017, 33, 1067.

6. Yi, Z.; Dume, L. F.; Garvey, C. J.; Feng, C.; She, F.; Rookes, J. E.; Mudie, S.; Cahill, D. M.; Kong, L.; Langmuir 2015, 31, 8478 .

7. Zhao, D.; Wan, Y.; Zhou, W.; Ordered Mesoporous Materials; Wiley-VCH: Weinheim, Germany, 2013.

8. Hao, S.; Chang, H.; Xiao, Q.; Zhong, Y.; Zhu, W.; J. Phys. Chem. C 2011, 115, 12873.

9. Hao, S.; Xiao, Q.; Yang, H.; Zhong, Y.; Pepe, F.; Zhu, W.; Microporous Mesoporous Mater. 2010, 132, 552.

10. Yokoi, T.; Yoshitake, H.; Tatsumi, T.; J. Mater. Chem. 2004, 14 , 951.

11. Yokoi, T.; Kubota, Y.; Tatsumi, T.; Appl. Catal., A 2012 , 421-422, 14

12. Kecht, J.; Schlossbauer, A.; Bein, T.; Chem. Mater. 2008, 20, 7207.

13. Gianotti, E.; Estevão, B. M.; Cucinotta, F.; Hioka, N.; Rizzi, M.; Renò, F.; Marchese, L.; Chem. - Eur. J. 2014, 20, 10921.

14. Wada, A.; Tamaru, S.; Ikeda, M.; Hamachi, I.; J. Am. Chem. Soc. 2009, 131, 5321.

15. Wanyika, H.; Gatebe, E.; Kioni, P.; Tang, Z.; Gao, Y.; Afr. J. Pharm. Pharmacol. 2011, 5, 2402.

16. Lu, J.; Li, Z.; Zink, J. I.; Tamanoi, F.; Nanomed. Nanotechnol. Biol. Med. 2012, 8, 212.

17. Vallet-Regí, M.; Rámila, A.; Del Real, R. P.; Pérez-Pariente, J.; Chem. Mater. 2001, 13, 308.

18. Rahman, Z. U.; Zhang, T.; Feng, Y.; Ye, W.; Wang, D.; ChemistrySelect 2017, 2, 3969.

19. Rahman, Z. U.; Wei, N.; Li, Z.; Sun, W.; Wang, D.; New J. Chem. 2017, 41, 14122.
20. Jabariyan, S.; Zanjanchi, M. A.; Ultrason. Sonochem. 2012, 19, 1087.

21. Vallet-Regí, M.; ISRN Mater. Sci. 2012, 2012, DOI: $10.5402 / 2012 / 608548$.

22. Pérez, L. L.; van Eck, E. R. H.; Melián-Cabrera, I.; Microporous Mesoporous Mater. 2016, 220, 88.

23. Estevão, B. M.; Cucinotta, F.; Hioka, N.; Cossi, M.; Argeri, M.; Paul, G.; Marchese, L.; Gianotti, E.; Phys. Chem. Chem. Phys. 2015, 17, 26804.

24. Björklund, S.; Kocherbitov, V.; Sci. Rep. 2017, 7, DOI: 10.1038/ s41598-017-10090-x.

25. Yildirim, A.; Ozgur, E.; Bayindir, M.; J. Mater. Chem. B 2013 , 1,1909

26. Image-Pro Plus, version 4.5.0.29; Media Cybernetics, Rockville, USA.

27. Thommes, M.; Kaneko, K.; Neimark, A. V.; Olivier, J. P.; Rodriguez-Reinoso, F.; Rouquerol, J.; Sing, K. S. W.; Pure Appl. Chem. 2015, 87, 1051.

28. Michaux, F.; Carteret, C.; Stébé, M.; Blin, J.; Microporous Mesoporous Mater. 2013, 174, 135.

29. Hudson, S.; Padera, R. F.; Langer, R.; Kohane, D. S.; Biomaterials 2008, 29, 4045.

30. Firouzi, A.; Kumar, D.; Bull, L. M.; Besier, T.; Sieger, P.; Huo, Q.; Walker, S. A.; Zasadzinski, J. A.; Glinka, C.; Nicol, J.; Margolese, D.; Stucky, G. D.; Chmelka, B. F.; Science 1995, $267,1138$.

31. Huo, Q.; Margolese, D. I.; Ciesla, U.; Demuth, D. G.; Feng, P.; Gier, T. E.; Sieger, P.; Firouzi, A.; Chmelka, B. F.; Schuth, F.; Stucky, G. D.; Chem. Mater. 1994, 6, 1176.

32. Musso, G. E.; Bottinelli, E.; Celi, L.; Magnacca, G.; Berlier, G.; Phys. Chem. Chem. Phys. 2015, 17, 13882.

Submitted: December 13, 2018

Published online: April 9, 2019 